\title{
A Justiça Militar do Brasil (*)
}

\author{
Thomaz Francisco Madureira \\ (Auditor de Guerra da 2.a Região Militar)
}

\section{O ELEMENTO HIST́́riCo}

O direito militar tem acompanhado a marcha evolutiva das civilizações e, as suas fórmulas, constantemente se renovam. Dos grandes exércitos como das grandes Nações, antigas e modernas, sentimos o empolgante das vitórias e as amarguras das derrotas, conquistas e destruições, que o pincel experimentando de Guglielmo Ferrero fixou para a maior Nação da antiguidade - no livro - "Grandeza e decadência de Roma" Mas, de tudo isso, nada mais resta que a poeira do tempo e sobre esta, pairando, a luz eterna da Justiça.

O eminente Pontalis não duvidou dizer que, si Roma subjugou á Europa com as suas armas, tambem a civilizou com as suas leis, de modo que, em duas direções supremas, os Romanos serviram os povos modernos: na legislação e na arte militar. E foi pelo exemplo de Roma que os povos civilizados na organização dos seus exércitos, no dizer do ilustrado CARCANI, criaram uma justiça especial, cujos progressos não se podem negar, porque todos os seus atos refletem a legislação penal comum.

Pietro Vico entende que não se póde concluir que seja o direito penal militar uma simples dependência do direito

(*) Conferência realizada na Faculdade de Direito da Universidade de São Paulo, em 22 de setembro de 1938. 
penal comum, ou melhor, "uma pura e exclusiva aplicação dos princípios reguladores do direito ás violações penais militares" E acrescenta: se o direito militar tem por campo de indagações os estudos de fatos especiais, é claro que, por isso mesmo, é distinto do direito penal comum Nem se diga da possibilidade de incluí-lo no direito particular, direito que se forma da matéria e várias leis especiais, reunidas em torno do Código penal ordinário, porque, enquanto o direito particular é comum a todos os cidadãos e, representa, em grande parte, o resultado das condições transitórias do Estado, o direito penal militar só se aplica aos cidadãos que têm a qualidade militar e não em carater transitório, momentâneo.

$O$ insigne Vicenzo Manzini ensina que seria um êrro evidente e gravíssimo qualificar o direito penal militar como um direito extraordinário e de exceção.

Também Esmeraldino Bandeira, seguindo de perto o grande mestre, nos diz que a advertência de Manzinı "bem consulta a fisionomia jurídica da legislação italiana e se ajunta, com propriedade, á feição atual do nosso direito repressivo militar e, porque o soldado não é uma exceção do homem, o direito penal militar não é uma exceção do direito penal comum" Por sua vez, o saudoso e notavel mestre da Faculdade de Direito do Rio de Janeiro, em sintese admiravel, escreve: "O soldado representa apenas uma categoria funcional de indivíduos, como o direito penal militar representa um capítulo especial da legislação penal militar; o soldado é um simples funcionário, e o direito penal militar uma simples especialização do direito penal comum. Assim, só a lei marcial que surge com a guerra é que forma um direito extraordinário e de exceção" Entre nós, o elemento histórico principal, a fonte do nosso antigo direito militar, foi a legislação portuguesa, que se encontrava nas Decisões da Côrte, nas Leis Gerais e Municipais, nos assentos da Casa de Suplicação e do Porto, no Código Afonsino, no Código Gótico, no Fuero Real, nas 
Leis dos Estilos, no Fuero Canônico, nas Leis das Sete Partidas e no Direito Romano.

Novas idéias vieram depois, tomadas por empréstimo á legislação francesa, ou tiradas da legislação italiana, mas tudo isso contribuiu para o desenvolvimento do nosso direito militar.

Da França, é o Código de 1889, sem esquecer as Ordenanças Reais que, em 1858, serviram de subsídio aos redatores do Código Militar

Da Itália, berço de juristas, é o Código Penal Militar de 1869, e, antes, o Código Sardo de 1 de Outubro de 1859 e o Código Penal Marítimo, promulgado pelo Decreto de 28 de Novembro de 1869.

Da Alemanha, é o Código Penal Militar de 20 de Junho de 1872 e, assim, o da Hespanha, cujas fontes são as Ordenanças e Instruções do Duque de Parma e Placência (Ord. de Farnésio, de 13 de Maio de 1887) sem esquecermos a Ordenança de Flandres de 1701 e a Ordenança Real de 1875 até a lei de 23 de Março de 1906 e a de 17 de Janeiro de 1901. Da Inglaterra, as Leis de 28 de Abril de 1882 e 26 de Abril de 1888, sendo que o Código Militar, antes de outras inovações, tinha sido promulgado em 1661 e completado em 1749, notando-se o fato de, em trinta e seis dos seus artigos, aplicar a pena de morte. Da grande nação amiga, a República Argentina, devemos recordar que a sua primeira Ordenança é de 25 de Março de 1810 e que, em 1898, principiou a ser cumprido o Código de Justiça Militar. Dos EstadosUnidos, cujo direito penal, na opinião de Von LISTZ, repousa sobre os mesmos fundamentos e apresenta as mesmas particularidades do direito inglês, não é possivel esquecer o Código de New-York de 1881, como, do Império do Japão, a lei de 1873 .

Este é, de momento, com as alterações trazidas pelo tempo, o acervo que nos poderá servir de auxílio, porém o nosso direito deve ser inteiramente nosso, a expressão da nacionalidade, cujos valores se descobrem em Tobias BARRE- 
to de Meneses e Ruy Barbosa, o norte e o sul do país, a Faculdade de Direito de Recife e a Faculdade de Direito de São Paulo.

\section{O FôRo MILITAR}

Theodoro Mommsen, no seu famoso trabalho "O Direito Penal Romano", não duvidou afirmar: A ciência jurídica dos romanos partia da idéia da plenitude do poder da magistratura. Assim, é de vêr-se que Roma distinguia entre a simples falta disciplinar cometida por militares e os delitos que de perto feriam a sociedade. E Jean Marsil adianta que, si um militar praticava crime de direito comum, por ele respondia diante de um tribunal mlitar que o julgava segundo as regras do processo criminal ordinário, aplicandolhe a pena correspondente.

Tambem o eminente Pessina informa que, no tempo do Império, com o enfraquecimento da civitas, entre as desigualdades, destacavam-se, justamente, os previlégios militares, o fôro especial. Cumpre, porém, colocar a questão nos seus devidos termos e, quem o faz, é a autoridade inconteste de Mommsen: "Não existia, no ponto de vista jurídico, diferença alguma entre o estado de paz e o estado de guerra. O soberano (rex) era o chefe único e vitalício que a comunidade possuia, originariamente, e que mandava e dispunha com inteiro e ilimitado poder, das infrações de natureza religiosa, militar ou civil, praticadas dentro ou fóra dos muros da cidade.

No L. I. \& 1 Digesto de re militare, encontram-se as seguintes penas: $O$ castigo, a multa, a transferência para outra milícia, a degradação, o rebaixamento, a expulsão por infâmia, porque os militares não podiam ser condenados a tortura nem ao trabalho das minas.

Os fatos puniveis, segundo o direito de guerra, eram os mesmos delitos praticados contra o Estado. A deserção e a sedição acham-se incluidos nos dois sistemas. A desobediência contra os mandados dos magistrados, desobediência 
que o direito geral não compreendia entre os delitos, ocupava, no direito de guerra, o primeiro logar. A evasão do campo da luta, como o abandono de posto, eram castigados com a pena de morte.

Na época republicana, o Direito Penal não admitia os delitos sexuais, e o furto era um delito que só se resgatava com a indenização pecuniária. No Direito de Guerra, pelo contrário, a injúria era um crime capital, tanto mais quando feria de perto a disciplina do Exército, o que, tambem, se poderia dizer do furto praticado no campo de batalha.

No regimen militar não se estabelecia a diferença entre o delito público e o delito privado. A conveniência e utilidades militares tinham, no direito de guerra, papel saliente, ocupando o elemento moral um logar secundário, embora sobre ele assentassem os fundamentos do direito penal civil ou de cidade.

E a partir do Direito Romano, as opiniões se dividem.

Para Oscar Pio têm o carater de crime propriamente dito militar, tendo-se em vista as circunstâncias especiais de que se revestem: - a corrupção, a falsidade, o ferimento, a calúnia, o furto e o estelionato. Os três primeiros dos mencionados crimes causam prejuizos á administração militar, e os demais, além do mal que trazem para o indivíduo, contrariam a ordem e a disciplina militar.

Tais crimes são infrações dos deveres comuns, com aquele carater, enquanto que a desobediência e a insubordinação dizem, bem de perto, dos deveres especiais do militar, e ocasionam prejuizos ao serviço militar.

Carcani lembra que, de acôrdo com as leis romanas, o militar, réu de um crime militar, devia ser julgado por um juiz militar, o que tambem se dava nos delitos comuns praticados em tempo de guerra.

No mesmo rumo está Paula Pessoa quando afirma: "Era excecional a jurisdição militar entre romanos. As causas civís ou criminais dos soldados cabiam, quanto ao julgamento, aos magistri militum, aos comitas e aos duces sob as 
ordens dos quais estes se achavam. Si os oficiais pertenciam á classe dos spectabiles, a apelação contra a decisão dos juizes devia ser dirigida á pessoa do Imperador quie pronunciava contra as sentenças dos judices ilustres, exceptuando-se as dos prefeitos do pretório, cujas decisões eram soberanas"

Esmeraldino BandeIra, tratando dos crimes militares, critérios e diferenciações, ensina: Originariamente os critérios de tais crimes desdobravam-se apenas em ratione materiae e ratione personae, parecendo filiar-se aquele ao direito romano primitivo e este ao direito germânico inicial. A aplicação de um e de outro dos referidos critérios, entre os respectivos povos, assentava na razão política de que, na Roma primitiva, o cidadão sobrelevava o soldado, ao passo que na velha Germânia o soldado sobranceava o cidadão. Assim, com a organização dos exércitos permanentes e com o desenvolvimento da disciplina do direito especial das forças armadas, os dois critérios se articulavam para a caracterização do crime militar. Depois disto, aparece o critério ratione loci que atribue fisionomia militar a certos crimes comuns praticados em logares de jurisdição militar, como quarteis, fortalezas, praças, navios de guerra e acampamentos.

Mas, depois de apreciar a definição romana do crime militar e do que denomina delitos impropriamente militares, os quais resultam do carater do agente, da espécie do ato praticado e do logar da execução, o conhecido penalista reconhece a impossibilidade de ser eliminada, de vez, a categoria dos crimes militares e de abolir os códigos especiais do soldado, julgando ser indispensavel reduzir as espécies de tais delitos e fundir, em um só código, todos os códigos especiais. Contra esta opinião insurge-se o talento adamantino de Gastão Bouniols. Para ele, o exército é distinto da nação, tanto pela existência como e, principalmente, pelas regras que lhe são próprias e, ainda, pelo seu aspeto. Assim, a justiça deve ser igual em seus princípios e fins, desde que use de formas diferentes e se dirija por outros caminhos. Não seria demasiado indicar o modo de ver de ANatole France, o 
grande estilista francês. Negava ele a existência da justiça militar e escrevia que o rexército está no mesmo nivel que a agricultura, as finanças ou a instrução pública. No entanto, o mais eminente dos nossos juristas, aquele que tem devassado, com o seu saber, todos os departamentos do direito, refiro-me ao imortal Clovis Bevilaqua, combate a opinião apressada de Anatole, que naturalmente a escreveu sob a impressão do processo de Dreifus, o solitário de Caiena, redivivo e imortalizado pelo talento fulgurante de Emilro Zola.

Para Clovis Bevilaqua ha classes sociais que têm uma criminalidade que lhes é própria e um direito primitivo que lhes é peculiar. Assim, a falência, "sendo fraudulenta ou culposa, é a forma especial da delinquência do comerciante, onde, como no Brasil, só os que fazem profissão de comércio se acham em condições de falir. Refere-se tambem, aos crimes "de função, impropriamente chamados die responsabilidade, que sómente por funcionários publicos podem ser cometidos" Para esses atos puniveis, ha sempre jurisdição especial, fórma distinta de processo e, algumas vezes, fôro prívilegiado. Tal é a conclusão do mestre.

Outros, como Faustin Helie não duvidam dizer que, da existência dos tribunais militares, depende a sã distribuição desta justiça, porém, o legislador não deve entregar a esses tribunais outros crimes que não sejam aqueles que, rigorosamente, lhes pertençam.

E, nesta ordem de considerações, alguns publicistas admitem que os delitos militares podem reduzir-se a duas espécies: os de ordem política e os de ordem moral. Os primeiros aniquilam o dever militar, enquanto os de ordem moral, os delitos comuns, cujo carater é mixto, prejudicando as pessoas, interessam a penalidade. Neste último caso, estão compreendidos os delitos praticados por militar contra militar e o roubo na caserna. Porem, é preciso não esquecer a opinião de JoÃo Barbal ho, o eminente constitucionalista, que, com segurança e golpes de vista invulgares, comentando o artigo 77 da Constituição de 24 de Fevereiro de 1891, es- 
creveu: "Para os crimes previstos pela lei militar, uma jurisdição especial deve existir, não como um privilégio dos indivíduos que os praticam, mas atenta a natureza desses crimes e a necessidade, a bem da disciplina, de uma repressão pronta e firme, com formas sumárias. A' existência das forças militares, liga-se a existência da Nação, como garantia de sua independência e segurança e, sem uma exata e constante disciplina, não cumprirão elas o seu importante fim. Sem uma jurisdição própria, privativa, militar, tambem, essa disciplina seria impossivel. A infração do dever militar é melhor compreendida por militares, porquanto no trato continuado da vida da caserna julgam com retidão da gravidade da falta e das circunstâncias que a cercam. Pelo que o fôro especial é uma condição de boa administração da justiça, tendo em conta que ele é só para os crimes que o cidadão pratica como soldado, pois, no militar, ha tambem o cidadão, e os fatos delituosos praticados nesta qualidade cáem sob a alçada da jurisdição comum a todos os membros da comunhão social" Entre nós, o legislador manteve o fôro militar quer no Imperio como na Republica, e, muito embora o $\S 177$ do art. 179 da Constituição de 1823 houvesse prescrito o fôro pessoal, o alvará de 28 de Julho de 1831, dispôs que, na falta de leis re regulamentos indicando os crimes de natureza militar, devia observar-se o privilégio nos casos não excetuados pelo direito. $\mathbb{E}$ não faltaram outros dispositivos legais, assim o art. $308 \S 2$ do Código Criminal de 16 de Dezembro de 1800, e os artigos 155 e 171 \& 1 do Código de Proclama de 29 de Março de 1823. Considerou-se crime militar o que só podesse ser cometido por cidadãos alistados nos cargos militares do Exército e da Armada. 0 artigo $90 \S 2$ das reformas introduzidas no Código die Processo de 3 de Dezembro de 1841 dispunha que não era permitida a revista das sentenças proferidas no fôro militar, pelo que mandava julgar oficiais e praças que tomassem parte nos crimes de rebelião e sedição. 
Na Provisão de 19 de Agosto de 1837, ficaram estabelecidos os casos em que o soldado brasileiro conservava o privilégio de fôro, afim de que fossem levados ás prisões militares, onde as houvesse.

Seria fatigante, prosseguir, enumerando leis, decretos, portarias e avisos.

E' preciso, porém, destacar a Lei número 2631 de 18 de Setembro de 1851, estabelecendo as penas e o processo dos crimes militares, bem como o regulamento de 30 do mesmo mês e ano, dispondo: A junta militar no conhecimento e decisão dos processos regular-se-á pelo Regimento do Conselho Supremo Militar; pela Lei de 18 de Outubro de 1827; pela Resolução de $10^{\circ}$ de Julho de 1830 , e leis em vigor. As sentenças do Conselho Supremo Militar, hoje - Supremo Tribunal Militar, eram executadas sem recurso algum, exceto o de graça, no caso da pena de morte.

$\mathrm{E}$, desde aquele primeiro momento, indicado no Código Criminal de 1823, até hoje, á justiça Militar do Brasil, representada pelos Juizes civis de antanho, que serviam no fôro militar e, posteriormente, pelos juizes togados, os auditores, isto é, toda a nossa magistratura, tem procurado pela disciplina do espírito honrar a toga, quer na paz como na guerra, e não receia hombrear-se com juizes militares nos Tribunais Militarles e, tanto o "cidadão-soldado, como o soldado-cidadão, procura, com o máximo cuidado, investigar os fatos e conhecer a verdade, aplicar a justiça, acertadamente, pelo muito respeito que lhes merece a soberania da lei".

\section{CóDIGOS E LEIS}

O Código de Organização Judiciária e Processo Militar (Decreto 15.635 de 26 de Agosto de 1892) marcando o início de uma nova fase no direito processual militar.

Anties da carta de Lei de 13 de Outubro de 1827, uma legislação confusa, que não mais se amoldava aos costumes da época, constituia o corpo doutrinário da Justiça Militar. Várias foram as tentativas de codificação. 
Destacamos o projeto de 1824, abolindo os privilégios pessoais dos militares e eclesiásticos. O projeto de Castro e Silva que extinguia o Conselho Superior de Justiça e modificava a mencionada lei. O de Nabuco de Araujo de 1850 e o de Magalináes Castro de 1860, o de Thomaz Alves de 1867 que tratava dos delitos e das penas militares, mas esquecia a organização judiciária e as leis do processo, descuido imperdoavel que, tambem, se verificou no substitutivo ao projeto de 1860, apresentado pelo Visconde de Uruguay. tivas.

Na República do mesmo modo não faltaram as tenta-

Lembramos, no entanto, o projeto de Carlos de Carvalho, de 1890; o de João Vieira de Araujo, de 1891; os de Barboza lima e Estevam Lobo, de 1905 , e o de Clovis Bevilaqua, de 1902, sem esquecer o projeto de Candido Motra, o ilustrado mestre desta Faculdade, de 25 de Agosto de 1911.

Em resumo. Dos Artigos de Guerra, do Código Lippe,

Reg. de Inf. de 1763, mandado observar em todas as armas pela Provisão de 11 de Outubro de 1873, alcançamos o Decreto numero 61 de 24 de Outubro de 1838 (aplicação das leis militares em tempo de Guerra); chegamos á Lei 631 de 18 de Setembro de 1851, aplicação das penas e o processo para alguns crimes militares, e, finalmente, ao Código Penal para a Armada, de 7 de Março de 1891, estensivo ao Exército, pela Lei 612 de 29 de Setembro de 1899.

$\mathrm{Na}$ parte processual bem poderiam ser lembrados, no antigo regimem, os Conselhos de Inquirição, de Disciplina, de Investigação e os Conselhos de Guerra, e, na República, quando do Reg. Proc. Crim. Mil. - os Conselhos de Investigação e os de Guerra.

Note-se, porém, que o Rieg. Proc. Crim. Mil., foi violentamente atacado em 1904 por Estevam Lobo, e, no Senado, pelo grande Ruy Barbosa, no seu memoravel discurso de 6 de Agosto de 1905 que assim o definia: "Sonolento e manquejante, com atrazos infinitos, a se arrastar aos tombos, trambolhando como lento carroção primitivo de bois escan- 
zelados, atravez de barrancos e pedregais, montanha acima, numa jornada interminavel de sertão a sertão".

U próprio Supremo Tribunal Federal o considerou inconstitucional, mas, como coisa intangivel continuou a ser observado até 1920, quando o eminente jurista EPITacio PessoA deu-lhe o golpe de morte, baixando o Decreto $\mathbf{1 4 . 4 5 0}$ de 30 de Outubro, aliás, posteriormente modificado pelo Decreto 15.635, de 26 de Agosto de 1922.

Foi assim que surgiu o Código de Organização Judiciária e Processo Militar que é, incontestavelmente, a linha divisória entre o direito antigo e o novo direito processual militar. Foram criados os Conselhos Permanentes, os Conselhos Especiais e os Conselhos de Justificação, e organizada a Justiça Militar, em tempo de guerra.

O Código de Organização Judiciária e Processo Militar tem sido imitado, fielmente reproduzido.

Seguiu-se-lhe o Código de Justiça Militar, ao qual se refere o Diecreto 17.231-A de 16 de Agosto de 1926, que, suprimindo a pronúncia, conservou a forma do processo e, mais de uma vez, reproảuziu a redação de artigos. Tambem este Código de Justiça Militar já sofreu algumas modificações pelo Decreto 24.803 de 14 de Julho de 1934, mas de modo algum se lhe alterou a substância. As novidades que trouxe foram: O julgamento dos insubmissos e desertores pelos Conselhos de Justiça organizados na unidade do culpado, bem como sobrestar o processo dos réus revéis quanto ao julgamento, e alterou alguns pontos do que entende com a organização dos Tribunais Militares em tempo de guerra. Por sua vez, o Decreto Lei 510 de 22 de Junho de 1938, apoiando-se no artigo 108 da Constituição de 10 de Novembro de 1937, estabelece os casos para o processo e julgamento dos civis em tempo de paz, no fôro militar.

Tal é o estado em que se encontra a legislação militar do Brasil.

Propositadamente não me referi á legislação militar em tempo de guerra, é assunto de maior relevância que deve 
ser examinado, cuidadosamente, em face do nosso direito e da legislação estrangeira.

\section{REFORMAS NECESSÁRIAS}

O Código Penal Militar como o Código de Justiça Militar, isto é, a lei substantiva e a lei adjetiva, estão a reclamar uma reforma mais inteligente. Os crimes devem ter melhor escolha e classificação; as penas melhor aplicação, e o processo, por sua vez, desembaraçado da velha formalística, cuja vantagem, única, é criar maiores embaraços. Assim, no crime de deserção, crime essencialmente militar, várias espécies que se encontram no Códigos estrangeiros e até mesmo, na Legislação Romana, não foram contempladas na lei brasileira. O complot de deserção, que figurava no direito anterior, foi suprimido. Ha prescrições que não se amoldam ao momento presente.

O legislador não considerou motivos e situações decorrentes e, sem exame, aplicou, para todos os casos, uma penalidade em tempo de paz, cujo limite só encontra paralelo na legislação espanhola. O prazo de graça nós não o possuimos. E' certo que, si a causa da ausência for justificada dentro de ôito dias, desaparecerá o crime de deserção, dando logar a uma falta disciplinar. Tambem o crime de insubmissão, tal como se encontra no Código Penal Militar, não deve subsistir. O numero de insubmissos é enorme, já em 1919 alcançava a cifra de 40.000. O Govêrno tem se visto na necessidade de baixar decretos de indulto para compôr esta situação anormal e afastar dos tribunais militares a sobre-carga de julgamentos inúteis, porque a falta de notificação da quasi totalidade dos sorteados, só por si, é suficiente para absolvê-los. Cumpre declarar que as Juntas de Recrutamento e Sorteio não podem, por dificuldades justificadas, dar completa execução ao dispositivo do regulamento em vigor. Seria mais racional que se modificasse a lei. 0 sorteado que não recebesse a notificação, quando preso ou apresentado expontaneamente, em lugar de um 
processo, diante do Comando da unidade, justificasse os motivos da sua falta que, comprovada, o levaria a inspeção de saúde, e desta dependeria a sua inclusão nas fileiras. Só seriam insubmissos os que huovessem sido notificados e não se apresentassem.

Quer me parecer que, além do exame clínico, o sorteado deve ser submetido a um exame psiquiátrico, evitando-se, por este meio, os elementos prejudiciais incluidos nas filèiras. A propósito, póde ser citado o livro de $C_{H}$. Pont. "Os indisciplinados no Exército", no qual estuda os indiscilinados anormais e focaliza a degenerescência, a demência precoce, a demência post-traumática, a paralisia geral, as intoxicações e, criteriosamente, lembra o tratamento adequado.

Quanto ás penitenciárias militares, os velhos cárceres devem ser destruidos e desaparecer, e, em logar de cada um deles, fundar-se a colônia agrícola militar, da qual nos dá notícia Carmelo Grossi, muito embora entre nós se encontrem sob outro aspeto nas antigas Colônias Militares, entre as quais a de Avanhandava, de 1858, cujo fim era estabelecer comunicações entre São Paulo e Mato Grosso, c a de Itapura, da qual faziam parte marinheiros e operários navais contratados.

Que a penitenciária agrícola possa resolver o problema dos condenados, dos que a sorte atirou para um recanto da sociedade, e que a todo o momento se revoltam, na ânsia da liberdade, na esperança de viver.

\section{A DISCIPLINA E A LEI}

A disciplina militar, no momento que passa, momento de angústia para todos os homens, para todos que cultuam o direito, póde ser definida: o laço moral que reune a multiplicidade dos deveres do indivíduo em face da Nação e tem, como resultante, a ordem social. 
Crisólito de Gusmão, tratando da disciplina, estabelece o seu paralelismo e conclue que a mesma tem por sanção jurídica - o direito militar e, como escopo, a estabilização e conservação e, além do mais, a tática e a organização das forças militares. Assim, surge este organismo vivo - o Exército, que não é uma organização passivamente obediente, feita e trabalhada pelo temor e pela punição.

Pallovitcr melhor a define no seu famoso livro - "O Ideal Democrático e a Disciplina Militar": -- A disciplina não é, simplesmente, feita de obediência passiva, porém, de inteligência e devotamento, e, assim, transforma e prolonga a obediência passiva em uma iniciativa subordinada aos interesses raramente expressos em conjunto. Torna-se uma virtude coletiva, o cimento da união moral, intelectual e física, que multiplica a fôrça de cada um pela fôrça de todos.

Vai longe o exemplo de Papirius mandando prender Fabius Rulianus, o vencedor dos Sánitas, e do perdão da culpa a ele concedido pelo povo romano. Vai longe a disciplina militar tal como a compreendiam os Persas, os Egipcios e as falanges Gregas.

Mas foi a disciplina militar pela boca de MARcus Lucullus, general romano, que, vendo a cidade de Amise, filha espiritual de Athenas, último recanto conquistado pelos romanos á Grecia, no ano de 71 , já entregues ao fogo e ao roubo, no meio de seus soldados enfurecidos, arriscando a própria vida, procurou salvar as obras de arte, o que não conseguiu, impondo, entretanto, a velha disciplina e evitando a morte dos habitantes da cidade.

Hoje, essa fôrça moral que dirige os homens para a luta, entre nós, tem como principal elemento a obediência, pois que, "recordando sempre as tradições nacionais, trabalhando todos em comum para o benefício do serviço, estimar-se-ão cada vez mais, prestando, assim, reciprocamente, na paz e na guerra, a necessária colaboração, pois, no momento preciso, saberão todos sacrificar-se pela Patria". 
Na "Retirada da Laguna", do Visconde DE TAunay, nome sobejamente conhecido na nossa literatura, encontrareis um dos livros mais brasileiros que já se tem escrito e apreciareis a nossa vitória moral, pois que, a material, já a possuimos, caminhando atravez do tempo, em marcha para o futuro, na epopéia grandiosa da raça que amanhece.

Entretanto, acima de tudo, serena e inflexivel, a soberania da lei que, na sua grandeza, póde ser comparada, si recordarmos as palavras do filósofo - a um ponto luminoso no meio da imensidade negra que nos envolve. Pois bem, que este ponto luminoso, ao lado da disciplina do soldado, ao lado da disciplina do cidadão, possa, entre nós, brilhar intensamente, por termos cumprido com desprendimento e coragem a sentença de IHERING:

A espada, sem a balança, é pura violencia, e a balança, sem a espada, a utopia do direito. 